\title{
A new species of Micadina Redtenbacher, 1908 (Phasmida: Necrosciinae) from Guangdong Province, China
}

\author{
George Wai-Chun Ho
}

\begin{abstract}
Ho, G. W. C. 2012: A new species of Micadina Redtenbacher, 1908 (Phasmida: Necrosciinae) from Guangdong Province, China. - Entomol. Fennica 23: 177-180.

Micadina cheni sp. n. is described and illustrated. It differs from other Micadina species by its unique spoon-shape of cerci. A key is given to males of all Chinese Micadina species.

G. W. C. Ho, Hong Kong Entomological Society, P. O. Box No.73749, Kowloon Central Post Office, Hong Kong; E-mail: georgehwc@hotmail.com
\end{abstract}

Received 20 February 2012, accepted 8 March 2012

\section{Introduction}

Studying the Chinese phasmids has become simpler since publication of two major works, a catalogue of species by Hennemann et al. (2008) and Chen and He's monograph (2008).

Redtenbacher erected the genus Micadina in 1908 (Redtenbacher 1908: 533). Thirteen species are recognized in this Palaearctic and Oriental genus distributed over Korea, Japan, Taiwan and China (Kwon et al. 1992, Otte \& Brock 2005, Hennemann et al. 2008, Chen \& He 2008, Ichikawa \& Okada 2008). Whilst collecting phasmids in primary forest in north Guangdong, China, an unnamed male Micadina was found. This new species is readily distinguished from other Micadina species by its spoon-shaped cerci. Accordingly, Micadina yingdeensis Chen and He, 1992 and M. cheni Ho sp. n. are presently recognized in Guangdong Province.

\section{Material and methods}

The specimens of the new species are deposited in Research Institute of Entomology, Zhongshan (Sun Yat Sen) University, Guangzhou, Guangdong, China (ZSU) and the private collection of
George, W. C. Ho, Hong Kong, China (GH). Morphological terms largely follow Bragg (1997, 2001).

\section{Genus Micadina Redtenbacher, 1908}

Type-species. Marmessoidea phluctaenoides Rehn, 1904: 73, by subsequent designation of Shiraki, 1935: 71.

Literature. Shiraki, 1935: 71 [Key to Japanese species]; Otte and Brock, 2005: 202; Ichikawa and Okada, 2008: 14 [Key to Japanese species]; Chen and He, 2008: 122 [Key to Chinese species].

Remarks. A key to males of Micadina is provided. Females are not included in the key as females have not been described for three species.

\subsection{Key to males of Chinese Micadina}

Adapted from Chen and He 2008

1. Anal segment longer than eighth tergum, cerci straight at base.

- Anal segment not longer than eighth tergum, cerci straight at base or slightly curved. 
a

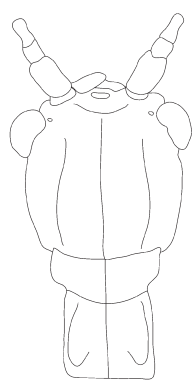

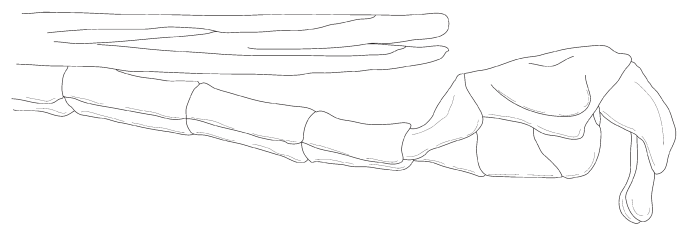

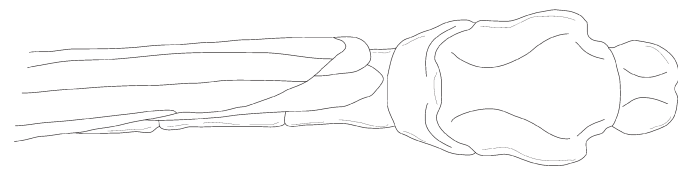

b Ho sp. n. - a. Male holotype, head and pronotum, dorsal view. $-b$. Male holotype, apical half of abdomen, lateral view. - c. Male holotype, apical half of abdomen, dorsal view. Scale bars $1 \mathrm{~mm}$.
2. Anal segment shorter than eighth tergum. 3 .

- Anal segment about as long as eighth tergum.

3. Cerci curved inward; apex of anal segment arched.

M. sonani Shiraki, 1935

- Cerci slightly curved, apex of anal segment truncate.

4.

4. Lateral margin of ninth tergum distinctly arched. M. fujianensis Liu and Cai, 1994

- Lateral margin of ninth tergum slightly arched. M. yingdeensis Chen and He, 1992

5. Cerci curved inwards.

M. zhejiangensis Chen and He, 1995

- Cerci straight. M. phluctaenoides Rehn, 1904

6. Cerci short, not exceeding the apex of anal segment.

- Cerci long, exceeding the apex of anal segment.

7. Hind half of anal segment nearly curved beneath. M. difficilis Günther, 1940

- Hind half of anal segment completely curved beneath. M. involuta Günther, 1940

8. Cerci straight, not spoon-shape.

M. bilobata Liu and Cai, 1994

- Cerci spoon-shape.

M. cheni Ho sp. n.

\subsection{Micadina cheni Ho sp. n.}

(Fig. 1a-c, Fig. 2a-b)

Type material. Holotype: $1 \lesssim$, Yueyun, Shaoguan, Guangdong Province, China, 19.VII.2008, Ho, G. W. C. (ZSU). Paratype: $1{ }^{\lambda}$, as holotype but $(\mathrm{GH})$.

Diagnosis. The new species is different from other Micadina species by postero-lateral angles of ninth tergum dilated into a triangular angle and cerci cylindrical at base, and broadened posteriorly in second half as spoon-shape.

Description. Male. Small. Body elongate, mainly green.

Head: Green, smooth, oval, longer than wide. Genae with a thin and brownish postocular stripe. Apical margin of frons as long as the first antennal segment. With a distinct small oval depression between the base of antennal segment, nearly as long as the length of second antennal segment. Occiput rounded and convex. Median furrow distinct, reaching to the hind margin of head. Eyes brownish, oval, big and prominent, longer than the first antennal segment. Ocelli indistinct, green, very small, placed above the eyes. Antennae brownish, long and filiform, segments indistinct; longer than fore legs, but shorter than body length; the first segment longer than third segment, cylindrical; second segment shorter than the first segment. Mouthparts orange.

Thorax: Pronotum green with a black mediolongitudinal stripe, rectangular, distinctly shorter and narrower than head, with distinct transversal and longitudinal sulcus crossing before middle, sparsely granulated, but granules not obvious; ventral surface smooth; anterior margin concave, hind margin truncate. Mesonotum mainly brown, also blackish with greenish, as long as the combined length of metanotum and median segment together, shorter than mesofemora, densely granulated, granules irregular size, medio-longitudinal carina distinct. Mesosternum without granules. Metanotum smooth. Prosternum, mesosternum and metasternum yellow.

Abdomen: Cylindrical and slender. Median segment shorter than metanotum. Almost parallel from second to seventh tergites with faint medio- 
Fig. 2. Micadina cheni Ho sp. n. - a. Male paratype, dorsal view. $-b$. Male paratype, lateral view.

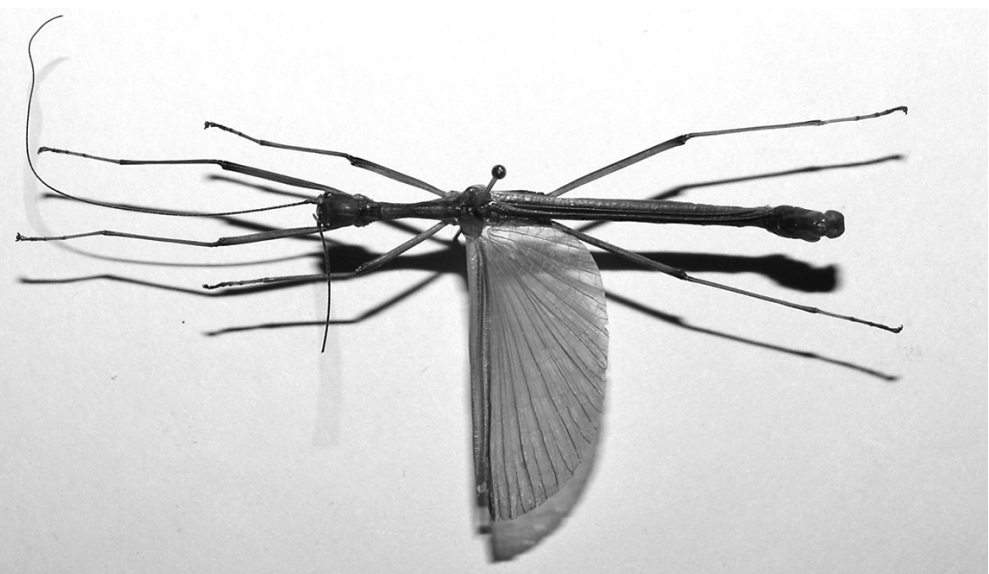

a

b

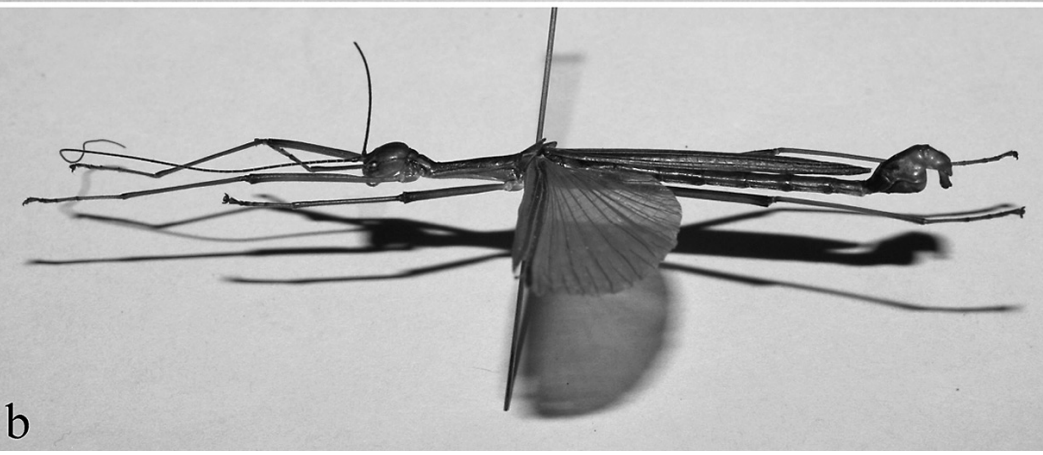

longitudinal carina. Eighth tergum expanded behind, with yellow edge, hind margin concave. Ninth tergum being the longest length, almost the combined length of eighth tergum and anal segment together, both sides slightly concave, postero-lateral angles dilated into a triangular angle from lateral view, hind margin rounded. Anal segment green, longer than eighth tergum, concave at hind margin, v-shape, the two lateral angles rounded, with setae. Poculum smooth, tapering posteriorly, apex rounded, reaching to the hind margin of ninth tergum. Cerci reddish brown, non-cylindrical, long and spoon-shape, straight and cylindrical at base, broadened posteriorly in second half, apices flattened and rounded, slightly curved inward, projecting over the end of anal segment.

Legs: Elongate and slender. All coxa orange. All femora dull green with rufous apices. All tibiae rufous with black tip. All tarsi rufous. Hind legs just projecting over the end of abdomen. Mid legs shorter than the length of alae.

Wings: Tegmina short, nearly half-length of metanotum, elevated portion distinctly protruded, black and blunt at tip, a short yellow line present beneath the black protruded angle. Alae long, reaching to the seventh tergum, costal region green, anal region dull rose.

Female. Unknown.

Measurements. Length (mm): Body length 40 , head 3.2, antennae 35 , pronotum 2.2 , mesonotum 6 , metanotum 4 , median segment 2 , profemora 10.5 , mesofemora 7.5 , metafemora 11 , protibiae 9.5 , mesotibiae 7 , metatibiae 10.5 , cerci 2.2., tegmina 2.5, alae 24 .

Distribution. Shaoguan, north Guangdong Province, China.

Etymology. Named in honour of Professor Chen Shu-chun for his extensive work on the Chinese phasmid fauna.

Acknowledgments. Deeply thanks to Paul Brock and an anonymous referee for their comments on the draft and Prof. Pang Hong (Head of Research Institute of Entomology, Zhongshan University), and Dr. Zhang Binglan, Mr. Xie Weicai, and Miss Tong Bo (Research Institute of Entomology, Zhongshan University) for their kind assistance. 


\section{References}

Chen, S. C. \& He, Y. H. 1992: Micadina yingdensis new species: a new walking stick injurious forest pest from Guangdong Province. - Forest Research 5: 207-209.

Chen, S. C. \& He, Y. H. 1995. — In: Wu, H. (ed.), Insects of Baishanzu Mountain, Eastern China: 63-68. China Forestry Publishing House, Beijing. 586 pp.

Chen, S. C. \& He, Y. H. 2008: Phasmatodea of China. Science Press, China. 476 pp.

Günther, K. 1940: Neue Stabheuschrecken (Phasmoïden) aus China. - Decheniana 237: 237-248.

Hennemann, F. H., Conle, O. V. \& Zhang, W. W. 2008: Catalogue of the stick and leaf-insects (Phasmatodea) of China, with a faunistic analysis, review of recent ecological and biological studies and bibliography (Insecta: Orthoptera: Phasmatodea. - Zootaxa 1735: 1-76.

Ichikawa, A. \& Okada, M. 2008: Review of Japanese species of Micadina Redtenbacher (Phasmatodea, Diapheromeridae), with description of a new species. Tettigonia 9: 13-31.
Kwon, Y. J., Ha, J. S. \& Lee, S. W. 1992: Classification of the order Phasmida from Korea. - Nature and Life 22: 43-58.

Liu, S. L. \& Cai, B. L. 1994: Descriptions of three new species of Micadina from China (Phasmatodea: Heteronemiidae). - Acta Entomologica Sinica 37: 87-90.

Otte, D. \& Brock, P. D. 2005: Phasmida Species File - Catalog of stick and leaf insects of the world. - The Insect Diversity Association and the Academy of Natural Sciences, Philadelphia. 414 pp.

Redtenbacher, J. 1908: Die Insektenfamilie der Phasmiden. III. Phasmidae Anareolatae (Phibalosomini, Acrophyllini, Necrosciini). — Verlag, Engelmann, Leipzig. 248 pp.

Rehn, J. A. G. 1904: Studies in the orthopterous family Phasmidae. - Proceedings of the Academy of Natural Science of Philadelphia 56: 38-107.

Shiraki, T. 1935: Orthoptera of the Japanese Empire (Part IV) Phasmidae. - Memoirs of the Faculty of Science and Agriculture, Taihoku lmperial University, Formosa $14: 23-88$. 